Forthcoming at Gender \& Society

\title{
The Gendered Consequences of a Weak Infrastructure of Care: School Reopening Plans and Parents' Employment During the COVID-19 Pandemic
}

\author{
Caitlyn Collins \\ Washington University in St. Louis \\ Leah Ruppanner \\ University of Melbourne \\ Liana Christin Landivar \\ Maryland Population Research Center \\ William J. Scarborough* \\ University of North Texas \\ *Note: All authors contributed equally to the preparation of this manuscript.
}

\begin{abstract}
The COVID-19 pandemic has upended in-person public education across the United States, a critical infrastructure of care that parents - especially mothers - depend on to work. To understand the nature and magnitude of school closures across states, we collected detailed primary data - the Elementary School Operating Status database (ESOS) - to measure the percentage of school districts offering in-person, remote, and hybrid instruction models for elementary schools by state in September 2020. We link these data to the Current Population Survey to evaluate the association between school reopening and parents' labor force participation rates, comparing 2020 labor force participation rates to those observed prepandemic in 2019. We find that, across states, the maternal labor force participation rate fell to a greater extent than that of fathers. In 2019, mothers' rate of labor force participation was about 18 percentage points lower than fathers'. By 2020, this gap grew by five percentage points in states where schools offered primarily remote instruction. We show that schools are a vital source of care for young children, and that without in-person instruction, mothers have been sidelined from the labor force. The longer these conditions remain in place, the more difficult it may be for mothers to fully recover from prolonged spells of non-employment, resulting in reduced occupational opportunities and lifetime earnings.
\end{abstract}

Keywords: mothers, employment, public schools, inequality, gender division of labor, COVID-19

Authors' Note: The Elementary School Operating Status (ESOS) database will be made publicly available via the Open Science Framework upon completion of data collection for all 50 states. The authors thank Jacob Sower, Lauren Ryan, Lloyd Rouse, Sheilla Njoto, and Nino Bariola for their invaluable assistance in web programming and collecting data for the ESOS database. The authors also thank the Texas Education Agency for providing us with detailed data on their school districts' reopening status in September 2020. 


\section{The Gendered Consequences of a Weak Infrastructure of Care: School Reopening Plans and Parents' Employment During the COVID-19 Pandemic}

As the COVID-19 pandemic dragged on through summer 2020 and into the fall and winter, school districts across the United States struggled to determine how best to provide safe, quality instruction to the nation's 50.8 million public school students (National Center for Education Statistics 2020). The deliberations about schools' reopening plans unfolded amid intense, and often competing, federal, state, and local pressures. The federal government pressured states to reopen schools for in-person instruction, in part, to allow parents to return to work. Some state governments, such as California, issued orders mandating online learning in counties where cases of COVID-19 remained high. Many states, such as Illinois and Pennsylvania, allowed for more local discretion in schools' reopening plans. Other states, such as Arkansas and Florida, mandated school reopening. As a result, school districts are operating with a wide variety of plans in the 2020-21 academic year, resulting in a patchwork structure of $\mathrm{K}-12$ education across the United States.

The unprecedented impact of COVID-19 on schools has underscored their critical role, not only for children's well-being, but also parents' employment - especially for mothers, who continue to do the bulk of caregiving in families despite working for pay nearly on par with fathers (Bianchi, Robinson, and Milkie 2006). Schools constitute the most expansive care infrastructure in the United States, and school closures and uneven reopening have affected mothers far more than fathers. Without alternative childcare arrangements or more participation from fathers, and with increased home-schooling demands, a staggering number of mothers have left the labor force (Alon et al. 2020; Heggeness 2020; Landivar et al. 2020; Petts, Carlson, and Pepin 2020). Maternal employment matters because it is vital for women's psychological 
wellbeing, economic independence, and lifetime occupational attainment and earnings (Killewald and Zhuo 2019). Some fear that the pandemic will unravel decades of feminist gains in the paid labor force for women (Kashen, Glynn, and Novello 2020).

Within this context, we ask: How is the country's patchwork approach to school reopening associated with mothers' employment? To answer this question, we draw upon our detailed Elementary School Operating Status database (ESOS) (unpublished data; publicly available upon completion of data collection in 2021) and the Current Population Survey (CPS) (Flood et al. 2020) to evaluate how labor force participation rates changed among mothers and fathers between 2019 and 2020 by state learning mode (remote, hybrid, or in-person). For illustrative purposes, we also identify three states with different approaches to reopening elementary schools as of September 2020-Maryland, New York, and Texas. As the 2020-21 school year began, Maryland reopened remotely across all school districts, whereas the majority of Texas' elementary students had the option of in-person learning. About half of elementary students in New York attended schools offering hybrid programs consisting of a mix of remote and in-person education (about two in-person days per week). What are the consequences of these different models? We describe parents' employment trends in these states to visualize how school reopening patterns track with paid work for fathers and mothers, comparing parents' labor force participation rates at the start of the 2019-20 (pre-pandemic) and 2020-21 school years. Then, we discuss these trends for the 26 states currently available in ESOS. We find mothers' labor force attachment worsened relative to pre-pandemic levels in states that offered fully remote instruction. As the pandemic continues into spring 2021, states with significantly curtailed in-person learning will likely continue to see low maternal labor force participation with the potential for devastating long-term employment effects for many women with children. 


\section{Work-Family Decisions Given a Weak Social Safety Net: Theorizing Maternal Employment Through a Capabilities Perspective}

We conceptualize the relationship between school pandemic reopening plans and maternal employment through a capabilities perspective, which posits that institutional constraints and opportunities can limit or enhance an individual's autonomy and self-actualization (Sen 1993; see also Hobson 2018; Morris 2002; Nussbaum 1999, 2000). By theorizing parents as embedded in institutional structures that both constrain and create opportunities (capabilities), we can understand how access to remote, hybrid, and in-person learning structures maternal employment. This approach urges us to consider not only mothers' choices regarding paid employment, but also how these decisions are shaped by institutional structures that can both hinder and facilitate opportunities (Hobson 2018). Drawing on a capabilities framework, we suggest that removing in-person education as a basic form of childcare provisions will impinge upon maternal employment in ways distinct from those of fathers.

School closures place a major institutional constraint on families to cover additional childcare. While the primary function of schools is children's education, they also provide an expansive infrastructure of care, especially for elementary school-age children (Schulte 2015; Slaughter 2015). Never before have schools closed to the extent or duration that we have observed during the COVID-19 pandemic. One in three U.S. women who left employment cite childcare demands as a primary reason for their departure (Heggeness and Fields 2020). We conceptualize mothers' labor force exodus as a deeply constrained choice, given women's limited capacity to engage simultaneously in paid work and around-the-clock care of children at home for months on end. Without more support from fathers, employers, and the government, something had to give under this unsustainable pressure. What seems to be giving is mothers' employment, with disastrous implications for their long-term earnings and occupational 
attainment (Kashen, Glynn, and Novello 2020). Although research is only now emerging that documents what the loss of in-person education means for parents' work outcomes, previous literature on preschool childcare offers crucial insight.

Expensive and inaccessible childcare hinders mothers' employment. Costly childcare increases mothers' odds of labor market exits and deters reentry, especially among single mothers and mothers with lower wages (Blau and Robins 1989; Han and Waldfogel 2001; Hofferth and Collins 2000; Landivar, Ruppanner, and Scarborough forthcoming). As a liberal welfare state that conceives of families and caregiving as private responsibilities, the United States is one of the only high-income countries without a public childcare system (Collins 2019). Across OECD (Organisation for Economic Co-operation and Development) countries, other governments are in agreement about the value of early childhood education and care, and make major investments to subsidize care accordingly. Absent a federal program, the long-awaited expansion of universal preschool in some U.S. municipalities shows just how central childcare is for mothers' employment. In Washington, DC, for example, the implementation of universal preschool for three- and four-year-old children has been linked to a remarkable 10-percentagepoint increase in maternal labor force participation (Malik 2018). Without a robust public childcare system, many women reduce employment when children are young and reenter the labor force when children reach school age (Bianchi 2000; Landivar 2017).

School schedules (i.e., length of school day) also shape maternal employment, and legislated school day hours vary across states (Ruppanner 2020). In states where school days are shorter, fewer mothers work for pay than in states with longer school days; and mothers who do work are more likely to do so part-time (Ruppanner, Moller, and Sayer 2019). For many, schools provide a critical institutional lifeline to maintain employment. Thus, remote learning during the 
COVID-19 pandemic is likely to be particularly detrimental to mothers' labor force supply and attachment, as they struggle to maintain paid work while supervising children's virtual schooling.

Early studies of parents' domestic allocations at the height of the first pandemic lockdown show that mothers picked up a larger share of housework, childcare, and homeschooling than did fathers (Carlson, Petts, and Pepin 2020; Heggeness 2020), which hurt their employment (Petts, Carlson, and Pepin 2020). Fathers' employment remained largely unchanged. Our research shows that even when both parents could telecommute, mothers reduced work time and were more likely than fathers to exit the labor force (Collins et al. 2020; Landivar et al. 2020). Mothers also reported greater increases in anxiety, depression, and disturbed sleep compared with fathers, especially after experiencing a job loss or an increased housework or childcare load (Ruppanner et al. forthcoming). Thus, preliminary evidence suggests that gender inequality in the domestic division of labor worsened under the pandemic. Mothers, on average, assumed the brunt of the added care at the expense of their paid work. Here, we add an important contextual dimension to this body of research: the role of school reopening plans for elementary-age children across U.S. states.

\section{How Did School Reopening Plans Shape Parents' Employment?}

In the absence of federal work-family policies, state governments often fill the void. This has long been true for social assistance programs, especially those intended to assist families and children (Ruppanner 2020), but it became even clearer during the COVID-19 pandemic. Federal support to families has been limited, and states have varied in their responses. This included divergent state approaches to slow the virus' spread, including school reopening strategies. Some states enacted more extensive remote learning plans (e.g., Maryland), while others adopted 
mostly in-person classes (e.g., Texas) or hybrid models (e.g., New York). In many states, reopening decisions were made at local levels, often school district by district. Although there is evidence that young children are not major transmitters of COVID-19 (Children's Hospital of Philadelphia 2020; Lewis 2020; Oster et al. 2020), a variety of factors led many districts to adopt remote or hybrid learning plans as the 2020-21 academic year began—namely, a lack of adequate resources to reopen schools safely, opposition to in-person learning among teachers' unions and some families, and consistently high levels of local virus transmission in some areas (Bond, Dibner, and Schweingruber 2020; Gewertz 2020; Tully 2020).

To illuminate this complex decision making, we collected data on school reopening at the local district levels to form the Elementary School Operating Status (ESOS) database (unpublished data; publicly available 2021). ESOS is a comprehensive database on school district reopening status with data for 26 states to date. Upon completion, ESOS will provide data on the reopening status of all elementary school districts in the country serving more than 500 students, or approximately 9,000 school districts, for all 50 states and the District of Columbia. ESOS indicates whether schools were operating fully remote, hybrid, or in-person programs as of September 2020. We aggregate school district data to the state level, weighted by student population size, to combine these data with the Current Population Survey (CPS) (Flood et al. 2020). We use CPS data for September through November in both 2019 and 2020 to match the first semester of each respective academic year. We restrict our sample to mothers and fathers ages 18-55 years with a youngest child 5-12 years (elementary school age). The sample size across all 26 states is 20,807 respondents in 2019 and 18,889 respondents in 2020 for a total sample of 39,696 . 
For illustrative purposes, we selected three states to show how parental labor force participation rates changed between the start of the school year in 2019 compared with 2020. In Figure 1, which compares 2019 with 2020, we report predicted probabilities of labor force participation for mothers and fathers with elementary school-age children (5-12 years old) during the first semester of the academic year (September, October, and November). These results were calculated from a logistic regression model including interactions between gender (mothers vs. fathers), year (2019 vs. 2020), and the three states we selected for illustrative purposes (Maryland, New York, and Texas). The model also includes controls for race (White, Black, Hispanic, other), age, marital status (married, not married), education (less than high school, high school, some college, college degree or more), and states' daily average cases of COVID-19 per 100,000 residents by month (obtained from the Centers for Disease Control and Prevention 2020).

Maryland reopened for the 2020-21 school year in fully remote status across all school districts. In this state, we observed the largest drop in the probability of mothers' labor force participation between the first semester of the 2019-20 school year and the 2020-21 school year. Mothers of elementary-age schoolchildren in Maryland were 16 percentage points less likely to be in the labor force during the first semester of the 2020 school year than during the same period of 2019 (from 90\% to 74\%; $p<0.05$ ). Fathers' aggregate labor force status also dropped, by five percentage points (from $92 \%$ to $87 \%$; n.s.), but this difference fails to reach statistical significance. 
Figure 1. Predicted Probabilities of Labor Force Participation for Mothers and Fathers with Elementary School-Age Children (5-12 years) During First Semester (September-November) of School Years 2019 and 2020
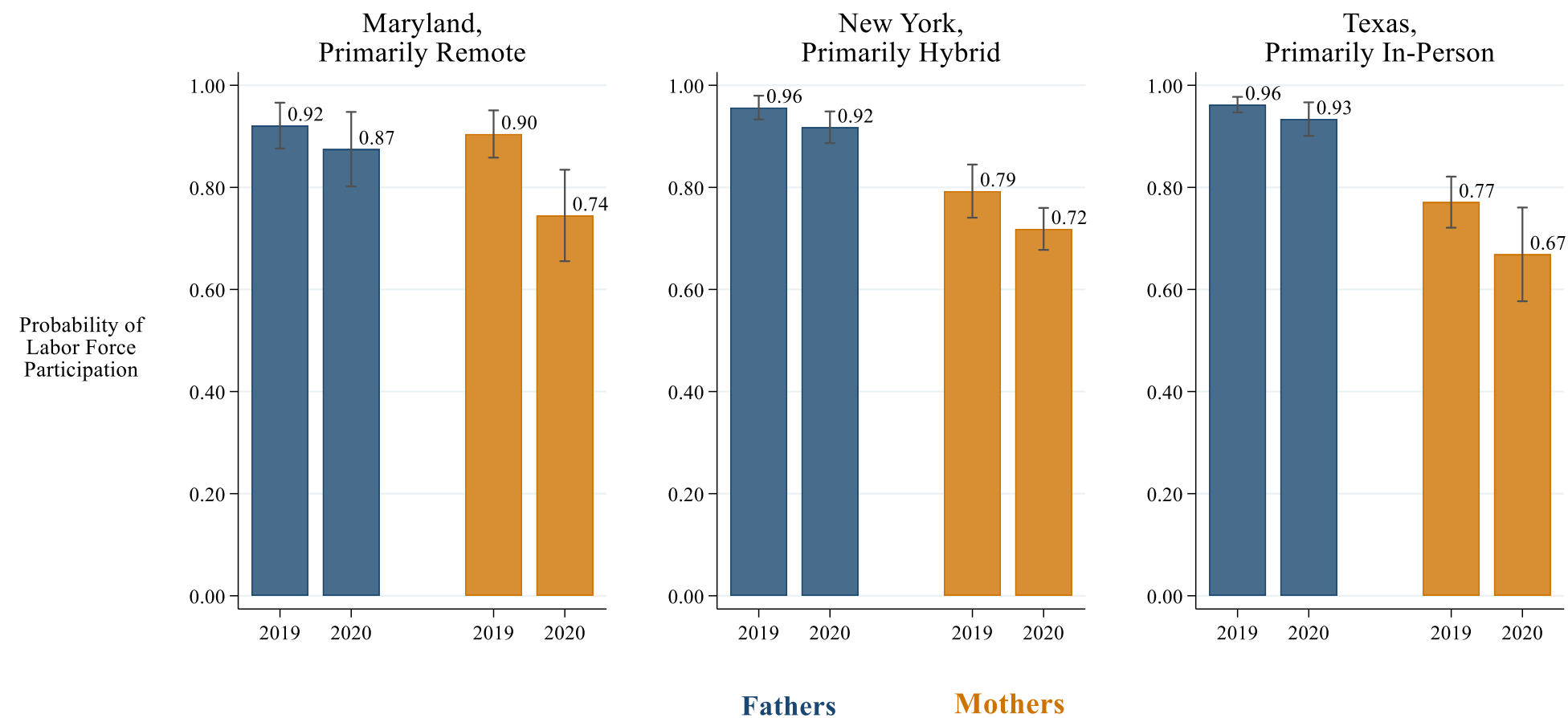

NOTE: Predicted probabilities of labor force participation calculated from logistic regression model with a three-way interaction between gender (mothers vs. fathers), state, and year with controls for race (White, Black, Hispanic, other), age, marital status (married or not married), education (less than high school, high school, some college, college degree or more), and states' daily average cases of COVID-19 per 100,000 residents by month. Data are from the Elementary School Operating Status database (unpublished data) and the Current Population Survey, months September, October, and November for 2019 and 2020 (Flood et al. 2020). Sample size: 5,966 (3,047 in 2019, 2,919 in 2020). Predicted probabilities of labor force participation surrounded by $95 \%$ confidence intervals (error bars). 
New York offered a variety of programs depending on the school district, with $50 \%$ of school districts opting for a hybrid program with in-person education twice per week. In this state, we found that mothers' predicted labor force participation declined by seven percentage points (from $79 \%$ to $72 \%$; n.s.), whereas fathers' was reduced by four (from $96 \%$ to $92 \%$; n.s.). Given the large standard errors in CPS state samples, neither of these shifts was statistically significant. Comparing New York with Maryland, the reduction in mothers' labor force participation was more than twice as large for mothers in Maryland, where schools were fully remote, than in New York where hybrid models predominated.

The third state we included in our model was Texas, where more than half of school districts offered their elementary students a full-time, in-person option (55\%). Fathers' labor force participation changed very little between 2019 and 2020 (96\% vs. 93\%; n.s.), whereas mothers' was reduced by about 10 percentage points (77\% to 67\%; n.s.) —a larger shift than observed in New York but one that is still nonsignificant and substantially smaller than the changes observed in Maryland.

Comparing Maryland, New York, and Texas reveals the important role schools play in providing a supplemental infrastructure of care for parents. When schooling goes fully remote, mothers' employment suffers. This is observed clearly in Maryland, where mothers' labor force participation was dramatically reduced during the first semester of the 2020 school year compared with the same period in 2019. Hybrid and in-person schooling in New York and Texas, respectively, were associated with a less dramatic reduction in mothers' labor force participation. Across all states, mothers' work attachment fell to a greater extent than did that of fathers, but the gap is widest in Maryland, where schooling was fully remote. 
Figure 2. Gender Gap in Parents' Labor Force Participation for Mothers and Fathers with Elementary School-Age Children (5-12 years) During First Semester (September-November) of School Years 2019 and 2020 for 26 States included in ESOS
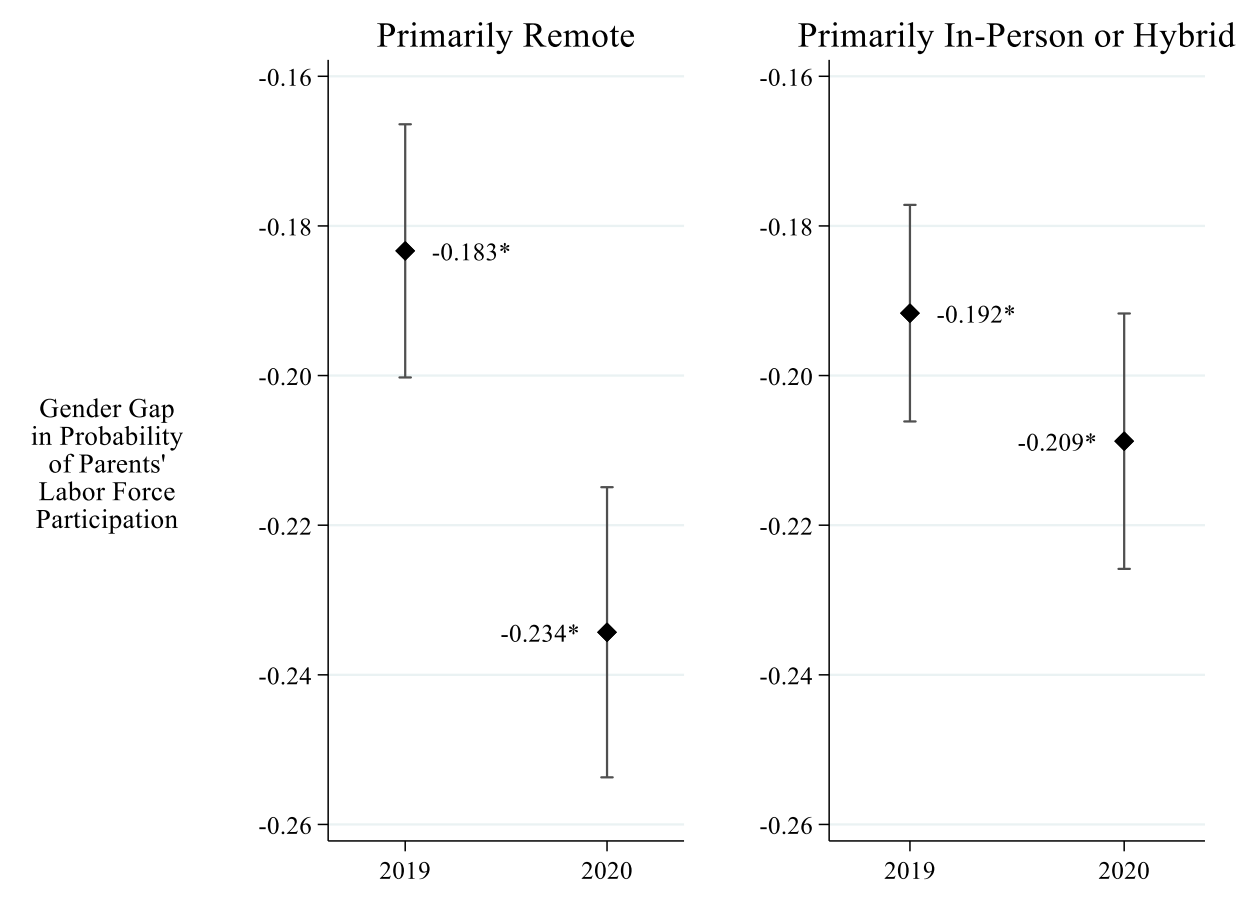

NOTE: Gender gap in labor force participation calculated from logistic regression model with a three-way interaction between gender (mothers vs. fathers), state-level school reopening status (primarily remote or hybrid and in-person), and year with controls for race (White, Black, Hispanic, other), age, marital status (married or not married), education (less than high school, high school, some college, college degree or more), and states' daily average cases of COVID-19 per 100,000 residents by month. Data are from the Elementary School Operating Status (ESOS) database (unpublished data) and the Current Population Survey, months September, October, and November for 2019 and 2020 (Flood et al. 2020). Sample size: 39,696 (20,807 in 2019, 18,889 in 2020). Sample is restricted to states included in ESOS: Alabama, Alaska, California, Delaware, District of Columbia, Florida, Georgia, Hawaii, Maine, Maryland, Montana, Nebraska, Nevada, New Mexico, New York, North Carolina, North Dakota, Ohio, Oregon, Pennsylvania, Rhode Island, South Carolina, Texas, Utah, Virginia, and West Virginia. ${ }^{*} p<0.05$ for gender gap in probability of labor force participation. Coefficients surrounded by $95 \%$ confidence intervals (error bars). 
When evaluating these patterns across the 26 states currently available in ESOS using the same modeling approach as with the three focal states, we find that the gender gap in parents' labor force participation grew the most in states where school instruction was primarily remote, and least in states where hybrid or in-person instruction were more commonly offered. The gender gap in the probability of labor force participation for parents of elementary school-age children (5-12 years old) during the first semester of the academic year (September, October, and November) is illustrated in Figure 2.

In 2019, the gender gap in parents' labor force participation was similar across each subset of states that later adopted different school reopening plans in 2020 during the pandemic, with mothers being about 18-19 percentage points less likely than fathers to be in the labor force. By 2020, we observe major differences across school reopening status. The gender gap grew by an additional five percentage points in states where school was offered mostly online $(p$ $<0.05)$, such as California, Delaware, and Virginia. Mothers' labor force participation dropped less in states that offered hybrid (e.g., Maine, New York, and South Carolina) or in-person instruction (e.g., Alabama, Florida, and Rhode Island), and the change in the gender gap in labor force participation was not significantly different between 2019 and 2020 in these states. States primarily offering hybrid or in-person instruction are combined for the presentation of our results as we do not yet have sufficient data to present statistically significant differences between these modes of instruction (Figure 2). We interpret our findings with caution as our data does not yet cover all 50 states and CPS state samples offer less robust estimates.

Our results show reduced employment and a growing gender gap in labor force participation in states offering fully remote instruction. We expected hybrid plans to be similarly 
disruptive of maternal employment, yet the gender gap in labor force participation shows little change in these states and no significant difference from states offering in-person instruction. When we examine school district-level data among states offering hybrid instruction in a majority of districts, in-person delivery was the second most common type of instruction (e.g., among students in New York, 50\% were in school districts offering hybrid instruction, 33\% inperson instruction, and $18 \%$ were fully remote). The significant presence of in-person options in states primarily operating hybrid programs may have lessened the impact of reduced in-person education in these states. On the other hand, employment could still be reduced in states offering primarily in-person instruction to the extent that this mode of instruction may have lower uptake among parents. Even as school districts reopened for instruction, many parents kept their children home out of safety concerns (Kroshus et al. 2020; Lohr 2020). This would reduce the positive association between maternal employment and in-person instruction. These issues should be explored as data become available. Our ESOS database, once complete, will be helpful in addressing some of these important questions.

\section{Reverting To Traditional Gender Norms? Future Research Directions}

Childcare and public schooling are fundamental forms of infrastructure that support families, businesses, and our economy (Folbre 2006). Without childcare and our public school system functioning as vital daily sources of care for the nation's children, it is difficult for families to have two earners, and for single parents to manage both paid work and caregiving. The erasure of the infrastructure of care-which was weak in the United States before the pandemic without a public childcare system like those of most high-income countries - through widespread school closures has caused many heterosexual-couple families to revert to traditional 
norms of fathers working and mothers caring for children. Here, we show that remote education had the most detrimental impact on maternal employment.

Although there is cross-state variation, maternal employment has suffered broadly during the pandemic. This is an injustice with long-term consequences for mothers' job prospects and economic stability. The burden on mothers is larger in some states than others, depending on the prioritization of public-school funding and reopening. These are not personal problems, but deeply political issues that require policy interventions. Well-funded and evidence-based reopening plans are necessary to allow children to return to school face-to-face, and to allow parents to engage in paid work. Federal and state governments can look to other nations for guidance where they prioritized continuity in in-person childcare and schooling during the pandemic (Bariola and Collins forthcoming). Now, more than ever, it is crucial that federal and state governments invest in expanding the public care infrastructure for children of all ages. 


\section{References}

Alon, Titan, Matthias Doepke, Jane Olmstead-Rumsey, and Michèle Tertilt. 2020. The impact of COVID-19 on gender equality. National Bureau of Economic Research, Working Paper No. 26947. DOI: $10.3386 / \mathrm{w} 26947$.

Bariola, Nino, and Caitlyn Collins. Forthcoming. The gendered politics of pandemic relief: Labor and family policies in Denmark, Germany, and the United States during COVID-19. American Behavioral Scientist.

Bianchi, Suzanne M. 2000. Maternal employment and time with children: Dramatic change or surprising continuity? Demography 37 (4): 401-14.

Bianchi, Suzanne M., John P. Robinson, and Melissa A. Milkie. 2006. The changing rhythms of American family life. New York: Russell Sage Foundation.

Blau, David M., and Philip K. Robins. 1989. Fertility, employment, and child-care costs. Demography 26 (2): 287-99.

Bond, Enriqueta C., Kenne Dibner, and Heidi Schweingruber. 2020. Reopening K-12 schools during the COVID-19 pandemic: Prioritizing health, equity, and communities. Washington, DC: National Academies Press.

Carlson, Daniel L., Richard Petts, and Joanna Pepin. 2020. Changes in parents' domestic labor during the COVID-19 pandemic. SocArXiv. DOI: 10.31235/osf.io/jy8fn.

Centers for Disease Control for Prevention. 2020. United States COVID-19 cases and deaths by state over time. https://data.cdc.gov/Case-Surveillance/United-States-COVID-19-Cases-andDeaths-by-State-o/9mfa-cb36 [accessed December 18, 2020].

Children's Hospital of Philadelphia. 2020. Policy review: Evidence and guidance of in-person schooling during the COVID-19 pandemic. Policy Lab. Last modified October 21, 2020. 
https://policylab.chop.edu/sites/default/files/pdf/publications/PolicyLab-Policy-Review-

Evidence-Guidance-In-Person-Schooling-COVID-19-Nov-2020.pdf.

Collins, Caitlyn. 2019. Making motherhood work: How women manage careers and caregiving. Princeton, NJ: Princeton University Press.

Collins, Caitlyn, Liana Christin Landivar, Leah Ruppanner, and William J. Scarborough. 2020. COVID-19 and the gender gap in work hours. Gender, Work \& Organization. DOI:

\section{$\underline{10.1111 / g w a o .12506}$}

Flood, Sarah, Miriam King, Renae Rodgers, Steven Ruggles and J. Robert Warren. 2020. Integrated Public Use Microdata Series, Current Population Survey: Version 8.0 [data set]. Minneapolis, MN: IPUMS, 2020. https://doi.org/10.18128/D030.V8.0

Folbre, Nancy. 2006. Rethinking the child care sector. Community Development 37 (2): 38-52.

Gewertz, Catherine. 2020. 'Schools need to be bolder' about reopening, public health expert says. Education Week, 2 November. https://www.edweek.org/leadership/schools-need-to-bebolder-about-reopening-public-health-expert-says/2020/11.

Han, Wenjui, and Jane Waldfogel. 2001. Child care costs and women's employment: A comparison of single and married mothers with pre-school-aged children. Social Science Quarterly 82 (3): 552-68.

Heggeness, Misty L. 2020. Estimating the immediate impact of the COVID-19 shock on parental attachment to the labor force and the double bind of mothers. Review of Economics of the Household 18: 1053-78. DOI: 10.1007/s11150-020-09514-x.

Heggeness, Misty L., and Jason M. Fields. 2020. Working moms bear brunt of home schooling while working during COVID-19. United States Census Bureau. Last modified October 30, 
2020. https://www.census.gov/library/stories/2020/08/parents-juggle-work-and-child-careduring-pandemic.html.

Hobson, Barbara. 2018. Gendered dimensions and capabilities: Opportunities, dilemmas and challenges. Critical Sociology 44 (6): 883-98.

Hofferth, Sandra, and Nancy Collins. 2000. Child care and employment turnover. Population Research and Policy Review 19 (4): 357-95.

Kashen, Julie, Sarah Jane Glynn, and Amanda Novello. 2020. How COVID-19 sent women's workforce progress backward. Center for American Progress, 30 October.

https://www.americanprogress.org/issues/women/reports/2020/10/30/492582/covid-19-sentwomens-workforce-progress-backward/.

Killewald, Alexandra, and Xiaolin Zhuo. 2019. U.S. mothers' long-term employment patterns. Demography 56: 285-320.

Kroshus, Emily, Matt Hawrilenko, Pooja S. Tandon, and Dimitri Christakis. 2020. Plans of US parents regarding school attendance for their children in the fall of 2020. JAMA Pediatrics 174 (11): 1093-1101.

Landivar, Liana Christin. 2017. Mothers at work: Who opts out? Boulder, CO: Lynne Rienner Publishers.

Landivar, Liana Christin, Leah Ruppanner, and William J. Scarborough. Forthcoming. Are states created equal? Moving to a less expensive childcare state increases mothers' odds of employment. Demography.

Landivar, Liana Christin, Leah Ruppanner, William J. Scarborough, and Caitlyn Collins. 2020. Early signs indicate that COVID-19 is exacerbating gender inequality in the labor force. Socius: Sociological Research for a Dynamic World 6 DOI: 10.1177/2378023120947997. 
Lewis, Dyani. 2020. Why schools probably aren't COVID hotspots. Nature 29 October. DOI: 10.1038/d41586-020-02973-3.

Lohr, Annaleise Azevdeo. 2020. Reuters/Ipsos: Schools reopening amid Coronavirus pandemic. Ipsos https://www.ipsos.com/en-us/reutersipsos-schools-reopening-amid-coronaviruspandemic-07162020.

Malik, Rasheed. 2018. The effects of universal preschool in Washington, D.C.: Children's learning and mothers' earnings. Center for American Progress. https://cdn.americanprogress.org/content/uploads/2018/09/14125635/Children-LearningMothers-Earning-report.pdf.

Morris, Patricia McGrath. 2002. The capabilities perspective: A framework for social justice. Families in Society 83 (4): 365-73.

National Center for Education Statistics. 2020. Fast facts: Back to school statistics. Institute of Education Statistics. https://nces.ed.gov/fastfacts/display.asp?id=372.

Nussbaum, Martha. 1999. Women and equality: The capabilities approach. International Labour Review 138 (3): 227-45.

Nussbaum, Martha C. 2000. Women and human development: The capabilities approach. Cambridge, MA: Cambridge University Press.

Oster, Emily, Galit Alter, Susan Johnson, and Lindsay Shultz. 2020. Kids and COVID-19: Summary overview. COVID-Explained. Last modified August 15, 2020. https://explaincovid.org/kids/kids-and-covid-19.

Petts, Richard, Daniel L. Carlson, and Joanna Pepin. 2020. A gendered pandemic: Childcare, homeschooling, and parents' employment during COVID-19. SocArXiv. DOI: 10.31235/osf.io/gwkzx. 
Ruppanner, Leah. 2020. Motherlands: How states push mothers out of employment. Philadelphia, PA: Temple University Press.

Ruppanner, Leah, Stephanie Moller, and Liana Sayer. 2019. Expensive childcare and short school days = lower maternal employment and more time in childcare? Evidence from the American Time Use Survey. Socius: Sociological Research for a Dynamic World 5. DOI: $\underline{10.1177 / 2378023119860277 .}$.

Ruppanner, Leah, Xiao Tan, William Scarborough, Liana Christin Landivar, and Caitlyn Collins. Forthcoming. Shifting inequalities? Parents' sleep, anxiety and calm during the COVID-19 pandemic in Australia and the United States. Men and Masculinities.

Schulte, Brigid. 2015. Overwhelmed: Work, love, and play when no one has the time. New York: Macmillan.

Sen, Amartya. 1993. Capability and well-being. In The quality of life, edited by Martha C. Nussbaum and Amartya Sen. Oxford, UK: Clarendon Press.

Slaughter, Anne-Marie. 2015. Unfinished business: Women men work family. New York: Random House.

Tully, Tracey. 2020. N.J. governor wants schools open. Local officials have other ideas. New York Times, 26 November. https://www.nytimes.com/2020/11/26/nyregion/nj-schoolsreopening-remote.html action $=$ click\&module=RelatedLinks\&pgtype=Article. 